\title{
Particle Sizes of Aerosols Produced by Nine Indoor Perfumes and Deodorants
}

\author{
Jean-François Bertholon ${ }^{1,2,6}$, Marie-Hélène Becquemin ${ }^{1,3}$, Monique Roy ${ }^{1}$, Francis Roy ${ }^{4}$, \\ David Ledur $^{5}$, Isabella Annesi-Maesano ${ }^{2,6}$, Bertrand Dautzenberg ${ }^{2,7}$ \\ ${ }^{1}$ Aerosols Particle Sizing and Lung Deposition Laboratory, Pulmonary Function Department, Paris, France \\ ${ }^{2}$ Epidemiology of Allergic and Respiratory Diseases Department (EPAR), Institut Pierre Louis d'Epidémiologie et de Santé Publique (IPLESP \\ UMRS 1136), Sorbonne Universités, Paris, France \\ ${ }^{3}$ Paris Diderot, University Paris Cité, Paris, France \\ ${ }^{4}$ SureDyna Montrouge, Paris, France \\ ${ }^{5}$ Ecomesure, Janvry, Paris, France \\ ${ }^{6}$ Medical School, Sorbonnes Universités, Paris, France \\ ${ }^{7}$ Pneumology Department, Assistance Publique Hôpitaux de Paris, Paris, France
}

\section{Email address:}

jean-francois.bertholon@upmc.fr (Jean-François B.), marie-helene.becquemin@psl.aphp.fr (Marie-Hélène B.), monique.roy.taranger@free.fr (M. Roy), francis.roy@centraliens.net (F. Roy), david.ledur@ecomesure.com (D. Ledur), isabella.annesi-maesano@inserm.fr (I. Annesi-Maesano), bertrand.dautzenberg@psl.aphp.fr (B. Dautzenberg)

\section{To cite this article:}

Jean-François Bertholon, Marie-Hélène Becquemin, Monique Roy, Francis Roy, David Ledur, Isabella Annesi-Maesano, Bertrand Dautzenberg. Particle Sizes of Aerosols Produced by Nine Indoor Perfumes and Deodorants. International Journal of Environmental Monitoring and Analysis. Vol. 3, No. 6, 2014, pp. 377-381. doi: 10.11648/j.ijema.20150306.11

\begin{abstract}
Air fresheners are very popular and their aerosols contain components known to be toxic but we lack data on their penetration in the lungs which is dependent on their particle sizes. Thus we measured the particles sizes of various indoor deodorants and/or perfumes and derived an estimation of their regional deposition in the lungs. We used an Electronical Low Pressure Impactor which can separate aerodynamic diameters as low as $0.006(6 \mathrm{~nm})$ and as high as $10 \mu \mathrm{m}$. For all of our samples, 82 to $99 \%$ of the total number of particles have sizes of less than $0.3 \mu \mathrm{m}$ and are thus susceptible to penetrate up to the smallest bronchi and alveoli: for a nose-breathing adult the probability of deposition in the airways of an aerosol with a MMAD of $0.2 \mu \mathrm{m}$ is of $30 \%$ of the inhaled quantity, of which $15 \%$ in alveoli and 3\% in the bronchi according to the ICRP model. These results suggest a deposition in the deep lung and thus a potential for diffusion into the blood for most of the tested products.
\end{abstract}

Keywords: Air Fresheners, Deodorizers, Vapors, Fumes, Airways Deposition, Indoor Pollution

\section{Introduction}

A very popular category of products (Air Fresheners, Deodorizers, scented oils, Liquid Aromas Scented candles, incenses..) promise to make our homes always smell fresh and to clean the air we breathe, by masking or destroying pollution particles and bad smells, some claiming also to induce relaxation and meditation. In fact, these devices are adding new particles to the air and various studies have shown that some of the numerous chemicals they carry are toxic.

These chemicals, which are not produced by natural or human activity but are increasingly present in households, want to fill a subjective need to purify and improve the smell of the environment: these "Air Fresheners"benefit from an enormous publicity and are produced with ever more sophisticated generators.

Their composition is mostly kept secret but studies have found they include toxic compounds (benzene, phtalates, formol, formaldehyde, acetaldehyde, naphtalene, terpene, synthetic perfumes as geraniol, citronnellol, polycyclic aromatic hydrocarbons, acroleine....) that could be absorbed through the skin or by inhalation [6-10] and increase the occurrence of asthma [6].

While particle size is a most important parameter for lung penetration of aerosols, the literature about it is poor with the exception of incenses, due to their widespread traditional use $[1,2]$. Thus, the goal of this work was to measure the 
particles sizes of various indoor deodorants and/or perfumes, from which we could derive an estimation of the sites of their deposition in the airways.

\section{Methods}

The generation of these indoor aerosols, be they «natural» or industrial, use different techniques and we considered a sample of each kind, all purchased in a Parisian supermarket:

1 Passive diffusion (" Aroma Diffusers », Essential oils) sometimes enhanced by electric heating (scented oil warmers): we used a "Lagoon coolness" (ED) (Fig. 1).

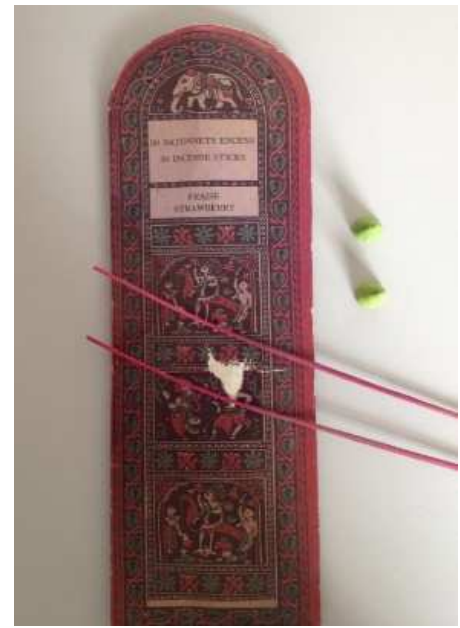

Figure 1. Incense sticks and cones.

2 Combustion of various products such as:

- «Armenian » paper: a resin (Styrax benzoin) dissolved in alcohol put on a blotting paper support: AP (Fig.2).

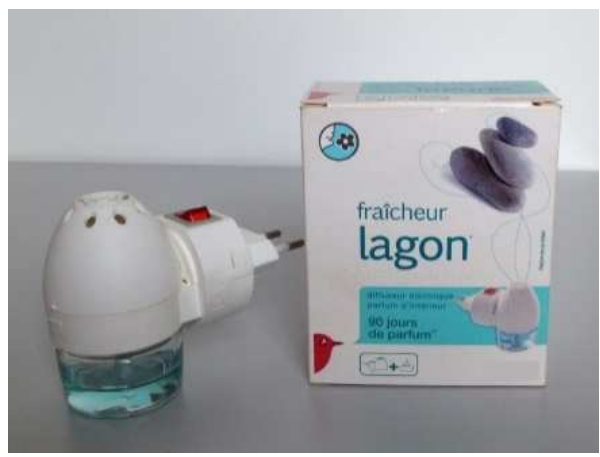

Figure 2. Plugged diffuser.

- Incense: Powdered resin or bark from some african and indian trees (Boswellia) consolidated with various additives in cone or stick shapes. This "natural" incense is now replaced by a neutral substrate dipped in a bath of synthetic perfumes.

- We tested a strawberry scented stick with an indian looking packaging (II) and another claiming an Ocean sensation on a simple sticker on a transparent plastic bag (OI). These two products bared no information about their composition (Fig.3).

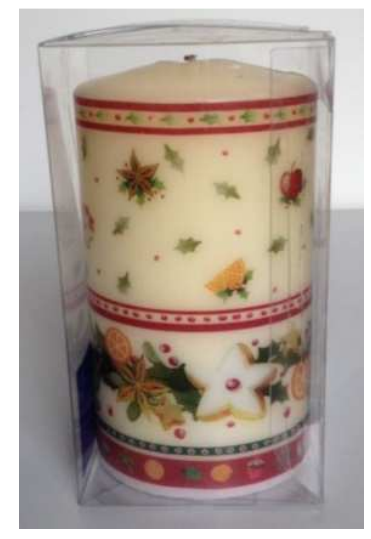

Figure 3. Non-scented candle.

- Candles: the burning wick melts the surrounding wax (most often colored paraffin derived from petroleum) which maybe specifically scented using essential oils or synthetic perfumes. We used a non-scented sample (C1) (Fig.4) and a scented ("peach and mango") one (C2) (Fig.5)

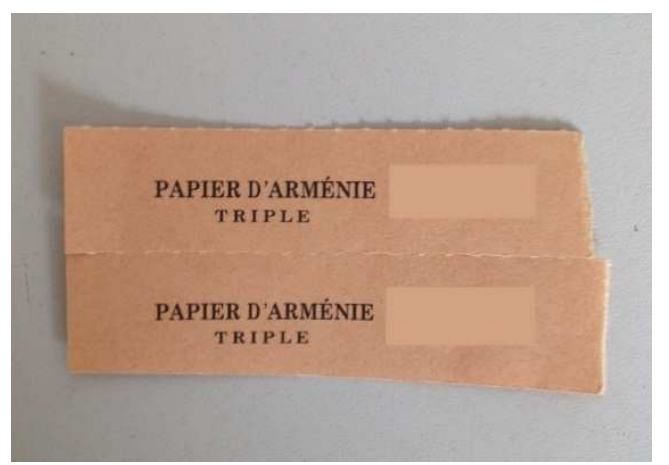

Figure 4. « Armenian » paper.

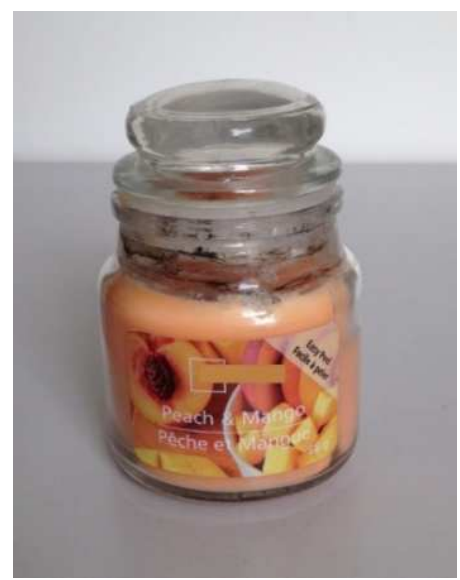

Figure 5. "Peach and Mango" candle.

3 Instant or automatic sprays from pressurized canisters. Since it is the most popular device, we used three types of deodorants from 3 different brands: "Bourbon vanilla and Cedar wood" (PC1) (Fig.6), "Essential oils vanilla flower and Caramel delight" (PC2) (Fig.7), "Nascent flower" (PC3) (Fig.8). 


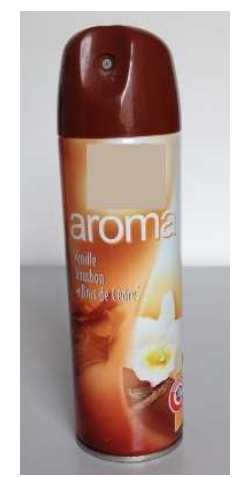

Figure 6. "Essential oils vanilla flower and Caramel delight".

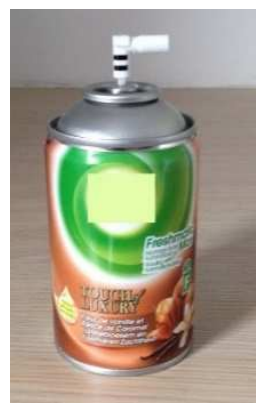

Figure 7. "Bourbon vanilla and Cedar wood".

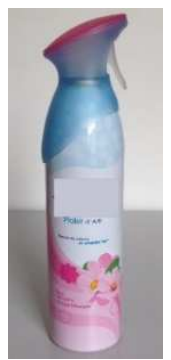

Figure 8. "Nascent flower".

The sizes of aerosol particles were measured using the Electronical Low Pressure Impactor (ELPI ${ }^{\circledR}$, Dekati Ltd, Tampere, Finland) which can separate aerodynamic diameters as low as $0.006(6 \mathrm{~nm})$ and as high as $10 \mu \mathrm{m}$ by impaction on 14 plates. The particles being electrically charged, a real time distribution of sizes and concentrations (in number) can be obtained.(Fig.9)

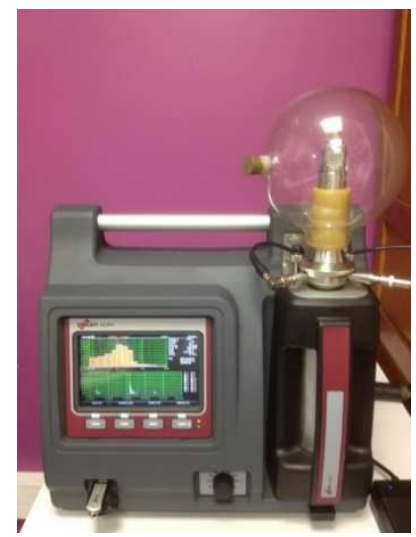

Figure 9. Particle sizer ELPI®, Dekati.
From the sizes spectrum, one derives the Mass Median Diameter (MMAD) in $\mu \mathrm{m}$ and the geometric standard deviation $(\sigma g)[3]$.

Our protocol used a spherical glass bottle (volume: 1.75 1) in which the aerosol was introduced and immediately analyzed by the ELPI (sampling flow $=10 \mathrm{l} / \mathrm{min}$. Sampling time 10s). After a series of tests aimed at determining the sampling method yielding an appropriate concentration of particles, we chose the following:

- Pressurized canisters: 1 short pulverization in the bottle. We used new canisters in order for them to function with the highest propellant gas pressure.

- Products with combustion : passive filling of the bottle during $10 \mathrm{~s}$ with the fumes of Armenian paper, incenses and candles,

- Electrical Aroma Diffuser: passive filling of the bottle during 2 min.

The sampling operations were carried out in a ventilated fume hood (Easter. Chemfree 2000) (Fig 10). After each measurement, the bottle was wiped and flushed with medical compressed air. (Fig.10) The testing room was aerated and the particle size distribution in the room air (background) was controlled before and after each series of aerosol measurements.

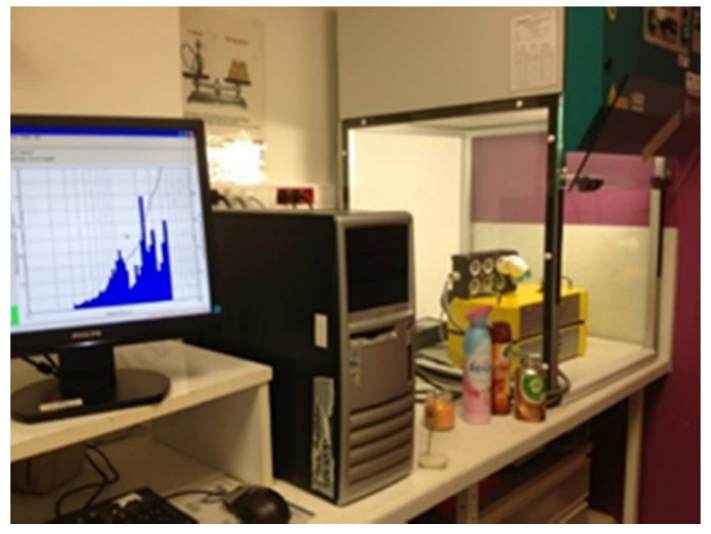

Figure 10. Ventilated fume hood.

Each measurement was repeated for stability checking and we give here the MMAD, the $\sigma g$ and the percentage ratio of the number of particles in each of four size classes $(<0.116$ $\mu \mathrm{m},<0.3 \mu \mathrm{m}$, between 0.3 and $2 \mu \mathrm{m}$ and $>2 \mu \mathrm{m}$ ) to the total number. These values were chosen according both to the ELPI specifications of sizes separation and to the environmental standards based on airway deposition

We then used a standard model (5) to estimate the fractions of deposition in the different lung regions and thus their impact on the airways and their potential for absorption in the blood stream.

\section{Results}

The results of our measures of particle sizes were:

- background: 19 measurements yielded a mean MMAD of $0.06 \mu \mathrm{m}$.

- aerosol samples : see Table I 
Table 1. Particle sizes and concentration percentiles in four size classes of indoor aerosols. ED: electric diffuser; AP, armenian paper; II et OI , «indian» and " ocean » incenses ; C1 and C2, non-scented and scented candles ; PC1, PC2 and PC3: deodorants from pressurized canisters.

\begin{tabular}{|c|c|c|c|c|c|c|}
\hline & \multicolumn{2}{|c|}{ Sizes $(\mu \mathrm{m})$} & \multicolumn{3}{|c|}{$\%$ of total number of sample particles } & \multirow[b]{2}{*}{$>2 \mu \mathrm{m}$} \\
\hline & MMAD & $\Sigma g$ & $<0.116 \mu \mathrm{m}$ & $<0.3 \mu \mathrm{m}$ & $0.3<>2 \mu \mathrm{m}$ & \\
\hline ED 1 & 0.42 & $>2.5$ & 93 & 96 & 4 & 0 \\
\hline ED 2 & 0.66 & $>2.5$ & 95 & 98 & 2 & 0 \\
\hline AP 1 & 0.18 & 1.94 & 94 & 97 & 3 & 0 \\
\hline AP 2 & 0.18 & 1.79 & 94 & 97 & 3 & 0 \\
\hline II 1 & 0.17 & 1.8 & 95 & 95 & 2 & 0 \\
\hline II 2 & 0.2 & 1.78 & 83 & 83 & 9 & 0 \\
\hline OI 1 & 0.35 & 1.6 & 77 & 82 & 18 & 0 \\
\hline OI 2 & 0.3 & 1.63 & 81 & 87 & 13 & 0 \\
\hline C1 1 & 0.09 & 1.96 & 95 & 98 & 1 & 0 \\
\hline C1 2 & 0.09 & 1.99 & 95 & 99 & 2 & 0 \\
\hline C2 1 & 0.09 & $>2.5$ & 96 & 98 & 1 & 0 \\
\hline C2 2 & 0.17 & $>2.5$ & 98 & 99 & 1 & 0 \\
\hline PC1 1 & 0.32 & $>2.5$ & 97 & 99 & 1 & 0 \\
\hline PC1 2 & 0.3 & $>2$ & 95 & 98 & 2 & 0 \\
\hline PC2 1 & 0.62 & $>2$ & 93 & 98 & 1 & 0 \\
\hline PC2 2 & 0.67 & $>2$ & 88 & 92 & 8 & 0 \\
\hline PC3 1 & 2.79 & $>2$ & 90 & 93 & 5 & 2 \\
\hline PC 32 & 2.05 & $>2$ & 95 & 98 & 2 & 0 \\
\hline
\end{tabular}

\section{Discussion}

The particle sizes spectrums can vary from one measure to the other for the pressurized canisters, the scented candle and the electric diffuser which all produce polydispersed aerosols with a high $\sigma \mathrm{g}$ while the other combustion aerosols are monodispersed with a $\sigma \mathrm{g}<2.5$ (Armenian paper, incenses, non-scented candle).

For all of our samples, 82 to $99 \%$ of the total number of particles have sizes under $0.3 \mu \mathrm{m}$ and are thus susceptible to penetrate down to the smallest bronchi and alveoli: for a nose-breathing adult the probability of deposition in the airways of an aerosol with a MMAD of $0.2 \mu \mathrm{m}$ is of $30 \%$ of the inhaled quantity, of which $15 \%$ in alveoli and $3 \%$ in the bronchi according to the ICRP model [5].

This study doesn't deal with their toxicity but shows through a particle size analysis that they may deposit very deeply in the lungs due to their very fine size. For 8 out of nine tested products, the MMAD is between $0.09 \mu \mathrm{m}$ and $0.67 \mu \mathrm{m}$, which leads to a deposition of $15 \%$ in the alveoli and a possibility of penetration in the blood depending on their chemical composition.

One recent product ( $\mathrm{PC} 3$ or Febreze ${ }^{\mathrm{TM}}$ ), generates bigger particles that should deposit more proximally in the airways. Its originality is to incorporate hydroxypropyl- $\beta$-cyclodextrin, which forms a « cage » trapping the odors.

The literature about particulate matter sizes from these products show results in accordance with ours: [11] studied church candles (paraffin and bee wax) using a differential mobility analyzer and a condensation nucleus counter and found most particles to be in the $0.01-0.1 \mu \mathrm{m}$ size range while the study of [12] concentrated on the dynamics of concentrations of particles produced by an air-freshener spray and candles. Particles from burning incense are better known with studies analyzing many different types of incenses $[1,2]$ which yielded MMADs between 0.26 and $0.65 \mu \mathrm{m}(0.17-0.35$ $\mu \mathrm{m}$ in our study).

Our study, using a new device is the first to report on the particle sizes distribution between $6 \mathrm{~nm}$ and $10 \mu \mathrm{m}$ of a sample of air fresheners and deodorizers and their deposition probabilities in the airways. The results confirm our previous findings concerning combustion smokes (tobacco), vapors (electronic cigarettes) and sprays from pressurized canisters (therapeutic metered doses sprays) [13-16] as well as those of $[11,12]$. More work is needed to assess the actual toxicity of these products, in particular the determination of concentrations of their chemical components in the blood after exposure. Concerning the airways, if these chemicals have noxious effects on them their will result from a chronic exposure and will not be apparent for a long time.

\section{Conclusion}

The toxicity of an aerosol depends upon (1) its chemical composition, (2) its particulate matter sizes - the bigger ones deposit in the airways and the smallest ones in the alveoli from where it may reach the blood stream - and (3) the mass concentration of particles during exposition. We report here the results of particles sizes for nine brands of air fresheners of various types.

Due the activity of this market, a study of air fresheners cannot be exhaustive but we may draw the broad conclusion that, considering their small particle sizes which result in their deposition in the deep lung and considering what is already known about some of their chemical components and their toxicity, they should be classified with tobacco smoke as major indoor air pollutants. 


\section{References}

[1] Y. Chi-Ru, L. Ta-Chang and C. Feng-Hsiang. 'Particle size distribution and $\mathrm{PAH}$ concentrations of incense smoke in a combustion chamber.' Environmental Pollution. 2007, 145, 606-615.

[2] J.J Jetter, Z. Guo, J.A. McBrian and M.R. Flynn. 'Characterization of emissions from burning incense.' Science of the Total Environment. 2002, 295, 51-67.

[3] A. Renoux. and D. Boulaud, 'Les aérosols. Physique et métrologie' Lavoisier Tech et Docs. 1998.

[4] US Environmental Protection Agency.US 2004 EPA Air Quality Guidelines. http://airnow.gov

[5] International Commission on Radiation Protection. Publication 66,.Pergamon Press, 1994 24, 1-3. 482.

[6] J.P. Zock, E. Plana, D. Jarvis., J.M. Antó, H. Kromhout, S.M. Kennedy et al. 'The Use of household cleaning sprays and adult asthma. An international longitudinal study.' Am J Respir Crit Care Med. 2007, 8,735-741.

[7] M. Lazaridis, V. Aleksandropoulou and J. Smolik, 'Physico-chemical characterization of indoor/oudoor particulate matter in two residential houses in Oslo, Norway: measurements overview and physical properties.' Indoor Air, 2006, 16,282-295.

[8] Scientific Committee on Health and Environmental Risks 2006 'Opinion on the report "Emission of chemicals by air fresheners. Tests on 74 consumer products sold in Europe.' January 2005".

http://ec.europa.eu/health/ph_risk/committees/04_scher/docs/s cher_o_026.pdf
[9] Natural Resources Defense Council. 2007 http://www.nrdc.org/health/home/airfresheners/fairfresheners. pdf

[10] F. Maupetit, and F. Squinazi. 'Caractérisation des émissions de benzène et de formaldéhyde lors de la combustion d'encens et de bougies d'intérieur: élaboration de scénarios d'exposition et conseils d'utilisation.' Environnement, Risques \& Santé, 2009, 8, 109-118.

[11] P.M. Fine, G.R. Cass and B.R.T. Simoneit. 'Characterization of fine particle emissions from burning church candles.' Environ. Sci. Technol. 1999, 33, 2352-2362.

[12] A. Afsari, U. Matson and L.E. Ekberg. 'Characterization of indoor sources of fine and ultrafine particles: a study conducted in a full-scale chamber.' Indoor Air, 2005, 15, 141-150.

[13] M.H. Becquemin, J.F. Bertholon, M. Attoui, F. Roy, M. Roy and B. Dautzenberg. 'Particle sizes in the smoke produced by six different types of cigarettes.' Rev. Mal. Respir, 2007, 24, 845-852.

[14] M.H. Becquemin, J.F. Bertholon, M. Attoui, F. Roy, M. Roy and B. Dautzenberg. 'Particle sizes in water pipe smoke.' Rev. Mal. Respir, 2008, 25, 839-846.

[15] J.F. Bertholon, M.H. Becquemin, M. Roy, F. Roy, I. Annesi Maesano and B. Dautzenberg. 'Comparaison de l'aérosol de la cigarette électronique à celui des cigarettes ordinaires et de la chicha. Rev. Mal. Respir. 2013, Doi: 10.1016/j.rmr.2013.03.003.

[16] A. Bouchikhi, M.H. Becquemin, J. Bignon, M. Roy and A. Teillac, 'Particle size study of nine metered dose inhalers and their deposition probablilities in the airways.' Eur. Resp. J. $1988,1,547-552$. 